\title{
As "mina" de Minas: acomodaçóes e resistências de mulheres nas Minas Gerais
}

\author{
Jorgetânia da Silva Ferreira* \\ Universidade Federal de Uberlândia, Uberlândia-MG, Brasil
}

Maia, Cláudia; Puga, Vera Lúcia (Org.). História das mulheres e do gênero em Minas Gerais. Florianópolis: Editora das Mulheres, 2015. $552 \mathrm{p}$.

Ler História das mulheres e do gênero em Minas Gerais é, antes de tudo, um prazer. As organizadoras, professoras mineiras, de distintas universidades de Minas Gerais, destacadas pesquisadoras acerca da temática de gênero - e suas intersecçóes — souberam construir muito bem essa obra, desde a escolha da belíssima capa que é um bordado coletivo, autorretrato de uma família de artistas. A diagramação e a impressão de qualidade propiciam uma leitura agradável. Os textos são bem escritos, a partir de documentação diversificada, e há rigorosa análise teórico-metodológica. Dividido em quatro partes e 22 capítulos, as organizadoras conseguiram relacionar estudos variados sobre as mulheres de Minas Gerais, em diferentes momentos históricos de forma articulada. Construíram uma colcha de retalhos, náo no sentido negativo, mas uma bela colcha em que cada parte foi bem costurada à outra, tornando o todo significativo para os/as leitores.
A partir de contribuiçóes de autoras e autores de diferentes áreas do conhecimento, especialmente da História, pudemos conhecer mais sobre mulheres em Minas - Estado considerado bastante conservador no que se refere às relaçóes de gênero —, não só nos aspectos que reforçam posiçóes/papéis/ funçôes tradicionais, mas, sobretudo, na problematização e na desconstrução desses lugares de mulheres. A obra permite-nos entrever - pelas frestas de portas e janelas mulheres arquitetando resistências, na busca da transformação ou mesmo fazendo uso dos modelos tradicionais para garantir seus interesses, e, sobretudo, sendo sujeitos de sua própria história.

Na primeira parte, "Transgressoras e insubmissas mineiras", refletimos com Diva do Couto Gontijo Muniz sobre trajetórias de mulheres que tiveram o magistério como profissão, as professoras de Minas Gerais. Embora estabelecido tradicionalmente como o lugar da mulher, cercado de regras e controles, visto como profissão para solteiras ou complementar ao orçamento familiar, Diva Muniz nos mostra que o magistério era "profissão que assegurava realização pessoal, relativa autonomia financeira, visibilidade

DOI - http://dx.doi.org/10.1590/2237-101X017033016

* Doutora em História Social pelo Programa de Estudos Pós-graduados em História da PUC-SP e professora do Instituto de História da Universidade Federal de Uberlândia (UFU). Uberlândia, MG, Brasil. E-mail: professorajorgetania@gmail.com. 
pública e conferia-lhes alguma distinção e respeito" (p. 27). Importante trabalho para pensar as relaçóes de gênero e educação e identidade profissional. Nesta mesma parte temos o interessantíssimo estudo de Vanda Lúcia Praxedes sobre mulheres concubinas de padres em que a autora busca dar visibilidade a essa temática presente no imaginário social, mas pouco analisada pela historiografia tradicional, nas palavras da autora. Destaca-se a riqueza do trabalho com testamentos e inventários das "mulheres de padres". O próximo capítulo, de Fabiana Francisca Macena, é sobre mulheres abolicionistas, e problematiza o papel das mulheres, especialmente das classes mais abastadas, nos eventos de interesse mais geral da nação. Macena discute as estratégias variadas de escravizadas para alcançarem a liberdade, deformando a imagem das mulheres como incapazes ou ausentes da luta abolicionista. Um capítulo destacado neste livro é o de Claudia Maia e Patrícia Santos, com o estudo da trajetória da feminista mineira Maria Lacerda Moura e sua crítica à família burguesa e à exploração feminina. As autoras analisam o papel dos discursos sobre a família na perspectiva do controle da vida das mulheres e do reforço das hierarquias de gênero. Para Maria Lacerda Moura: "A família servia, dessa forma, para assegurar a sujeição e a dependência das mulheres aos homens" (p. 98), passando-a da autoridade do pai à do marido. Para romper com esse lugar, as mulheres precisavam ser "desertoras da família”.

Ainda nesta parte do livro temos um trabalho que articula a relação entre literatura e loucura, a partir da obra Hospicio é Deus, de Maura Lopes Cançado. Neste artigo escrito por Márcia Moreira Custódia e Alex Fabiano Correia Jardim, "as angústias de uma mulher fora de seu tempo, resistente a uma identidade plasmada pelos ditames e desígnios de um modelo sociocultural..." (p. 130131) são debatidas e visibilizadas retratando as dificuldades de Cançado de conviver com o olhar hostil da sociedade mineira, o que a leva ao adoecimento e a diversas internaçóes, tornando sua obra importante para pensar mulheres e loucura.

No texto de Constância Lima Duarte, "Gênero e violência nos contos de Conceição Evaristo", vislumbramos uma discussão inovadora acerca de "sensíveis releituras da violência inspiradas no cotidiano feminino e formuladas a partir de uma perspectiva étnica e feminista" (p. 146), presentes em poemas e outros textos literário dos Cadernos Negros, publicados desde 1978. Ao tratar essa temática difícil para as mulheres, tantas vezes vítimas da violência de gênero, etnia, classe, geração, os Cadernos Negros o faz, segundo a autora, de maneira a denunciar a violência, mas também como "porta-voz da esperança de novos tempos" (p. 149). O trabalho cuidadoso torna o capítulo interessante de ser lido.

Finalizando a primeira parte temos o trabalho de Varlei Rodrigo do Couto, "Nas dramaturgias do prazer: a escrita de si como trajetória política", cujo título diz mais sobre a perspectiva teórica do que sobre o objeto de estudo. Couto aborda a campanha de moralizaçáo contra a zona de meretrício na cidade de Pouso Alegre, no final dos anos 1960, 
a partir da correspondência de prostitutas. Embora haja uma tentativa de encaixar as experiências dessas mulheres na perspectiva teórica, o estudo contribui para trazer à luz a fala de mulheres como Julieta, que escreve: "não consigo entender por que as pessoas quando me olham não vê a Julieta, mas vê minha vagina (...) é só ela que eles vê. É só isso que eu não gosto por que eu sou mais do que ela" (p. 172).

A segunda parte do trabalho intitulada, "Damas, donas do sertão", é constituída de três capítulos, sendo o primeiro escrito por Gilberto César de Noronha. O autor discute a trajetória de Joaquina de Pompéu, problematizando visóes sobre essa mineira que rompeu tradiçóes e se tornou fazendeira e comerciante importante de Paracatu. Seria ela "Dama do Sertão ou Sinhá Braba, mulher má?". Sem desconsiderar as múltiplas possibilidades de leitura, o autor ressalta que a imagem de "Sinhá Braba", embora incômoda para a memória da família e da cidade, "pode colocar em xeque um ideário luso-cristão, católico - e agora, liberal burguês de mulher-mãe, dona de casa, profissional austera" (p. 204). Ajuda, portanto, a desconstruir o lugar tradicional estabelecido para as mulheres, entrevendo nessa trajetória resistências ao poder masculino, ainda que talvez seja esse o modelo de referência usado por Joaquina de Pompéu.

Outro interessante trabalho é "Dona Tiburtina de Andrade Alves: de 'guerrilheira sertaneja' à 'cívica brasileira", de Maria de Fátima Gomes Lima de Nascimento e Filomena Luciene Cordeiro Reis, que recupera a trajetória de uma mulher, que ganhou noto- riedade política e social em Montes Claros após um episódio em 1930, quando foi acusada de tentar assassinar o vice-presidente da república. A análise das autoras privilegia as representações construídas sobre Tiburtina como fera, bandida, mentirosa, terrorista etc. como estratégia de esvaziar a oposição liberal e o poder político que ela e o marido representavam com vistas a "desestruturar a campanha liberal em Minas Gerais" (p. 223). O estudo nos leva a pensar sobre como era, e continua sendo difícil às mulheres participarem da política, pois são objeto de deboche, de chacota, de violência física e psicológica, sendo convidadas a se retirarem desse espaço que não é considerado seu.

O terceiro e último capítulo da segunda parte é de Telma Borges, e busca discutir nos contos de Guimaráes Rosa "A vela do diabo" e "Desenredo", presentes no livro Tutameia, os estratagemas femininos "que nos permitem ler o conjunto de contos que enfeixam esse livro como uma espécie de desenredo crítico à tradição - tanto a literária quanto a patriarcal" (p. 245). A partir de um trabalho com História e Literatura, a autora consegue apontar dissidências na construção social sobre as mulheres na obra de Guimarães Rosa.

"Saberes e fazeres femininos" nomeia a terceira parte do livro. Inicia com o estudo de Lúcia Helena Rodrigues Costa sobre as parteiras do norte de Minas, construído a partir de suas narrativas. Aponta as modificaçóes vivenciadas pelas mulheres na experiência de partejar, que migrou do domicílio para o hospital e de uma experiência familiar compartilhada para um local impessoal e "frio". 
O texto é importante referência para a reflexão do que se convencionou chamar "parto humanizado" e para o estudo das relaçóes/ tensôes entre saberes populares e científicos.

O capítulo denominado "O Congado me chamou: trajetórias e memórias das mulheres congadeiras de Ituiutaba-MG", de Cairo Mohamad Katrib e Fernanda Domigos Naves, discute o papel das mulheres no Congado, mostrando-as à frente dos ternos. O trabalho nos leva a pensar que, se por um lado as mulheres vivenciam esse protagonismo, por outro lado se espera delas uma função tradicional como cozinhar durante a festa, costurar, bem como ser "esteio familiar e quem alavanca a força do grupo para continuar difundindo suas raízes religiosas e ancestrais frente às agruras cotidianas" (p. 293). Os relatos apontam para a importância da identidade cultural no enfrentamento das "agruras" da vida. O estudo consegue, assim, nos aproximar da experiência dessas mulheres, em geral, pobres e negras, tantas vezes "invisibilizadas".

No capítulo "Comida e gênero: reflexão sobre mulheres e cozinha em Minas Gerais", Mônica Chaves Abdala destaca as transformaçôes nos modos de vida e na alimentação, apontando a terceirizaçáo via self service como a solução "à mineira" para a não divisão do trabalho doméstico. De acordo com Abdala, "as novas geraçôes se organizam de maneira a dividir mais as tarefas domésticas, em função de projetos dos quais ninguém está disposto a 'abrir mão' " (p. 323). A autora tem uma visão positiva sobre a distribuição do trabalho doméstico na atualidade, que caminharia para maior equidade de gênero. Por onde "andei" ainda vejo muito mais as mulheres na cozinha, e muitas vezes mulheres impedidas de construírem seu percurso de maneira mais livre em função da rigidez dos papéis tradicionais. Como afirma a própria Abdala, a mudança no ambiente doméstico tem sido lenta e aparece com mais clareza nos setores médios escolarizados. Nos meios populares, a concentração do trabalho doméstico na figura da mulher é mais visível.

Com o título "Trabalhadoras rurais no Triângulo Mineiro: atuações (in)visíveis”, Maria Andréa Angelotti Carmo discute a inserção da mulher nos processos de expansão e modificaçôes na agricultura na regiâo estudada, a partir das fontes orais, como parte de uma pesquisa mais ampla sobre os chamados boias-frias. A autora reconhece que não enfocou as relaçôes de gênero em seus estudos, o que náo a impediu de contribuir para a visibilidade de mulheres que "combinavam às tarefas da lavoura cafeeira o cuidado com os filhos e todas as atividades domésticas, mas não eram reconhecidas neste processo" (p. 334). Embora a trabalhadora rural esteja presente na lavoura, não há uma distribuição igual no âmbito doméstico, conforme aparece na fala de Nadir: "Se precisar fazer uma cerca a gente faz; se precisar de capinar, a gente capina, mas o serviço doméstico sou eu e minhas meninas" (p. 341).

João Augusto Gonçalves dos Santos, em "Rebeldia, dissidência e cura nos relatos femininos de fundação de Igrejas Pentecostais em Montes Claros", analisa a importância das mulheres para a estratégia de ramifi- 
cação das igrejas e as ambiguidades desse processo que, nas palavras do autor, são mulheres "silenciadas pelo discurso religioso e ausentes dos cargos de poder nas igrejas, são a maioria entre seus praticantes" (p. 346). O estudo traz depoimentos de mulheres com papel destacado, como o de Geralda Pinheiro "...a primeira sede dá no meu quintal. Eu ganhei muitas almas para o Senhor Jesus. (...) Eu tinha muita liberdade para isso e fazia o trabalho contente. (...) E eu estava à frente" (p. 359). Até o dia em que o pastor a convida para participar de uma reunião de obreiros na sede da igreja e indaga se ela aceitaria o pastor Antônio Froes para "ajudá-la". Ela aceitou. "Preferia ser apenas uma auxiliadora do pastor" (p. 360). Geralda é constrangida a sair do lugar "à frente" para a função de auxiliar.

"Recebi um diploma, realizei um sonho: mulheres e educação de adultos em Januária”. Com esse título, Leila de Souza Almeida aborda a exclusão educacional a que foram submetidas mulheres pobres no Brasil, com rico trabalho de campo, a partir das histórias de vida de 20 mulheres. Destaca-se a sensibilidade da autora na escuta dessas experiências de pessoas que adiaram por décadas o sonho de estudar: "Sofri dificuldade e discriminação por parte de meu marido, que não gostou da ideia. Ele dizia quando eu saía para estudar: isso é coisa pra puta, coisa de 'rapariga', que sai atrás dos machos à noite" (Dália, p. 375). Se as mulheres hoje são maioria no meio educacional, é preciso considerar a luta de mulheres que vieram antes de nós, que pavimentou esse terreno, tornando mais fácil o caminhar. Apesar do avanço é preciso considerar também que a cultura machista ainda faz sombra sobre o desejo das mulheres de viver suas vidas com liberdade.

Finalizando a terceira parte do livro, Maria Clara Tomaz Machado e Paulo Sérgio Moreira da Silva abordam a história de luta da família Amaro pela retomada de suas terras no município de Paracatu, sobre as quais tinham posse desde o século XVIII. Analisam os mecanismos de exploração utilizados pelos fazendeiros para expulsá-los das terras, bem como as acomodaçóes e resistências dessa família. Nessa luta ganha relevo a política desenvolvida pela Fundação Cultural Palmares na discussão - polêmica - acerca dos "remanescentes de quilombos". O trabalho é bastante instigante.

A quarta e última parte do livro é intitulada "Casamentos e maternidade" e compóe-se de cinco capítulos. No primeiro deles, Helen Ulhôa Pimentel aborda "O divórcio setecentista e a questão de gênero" a partir da análise de documentação produzida pelo Tribunal Eclesiástico, preservada no Arquivo Público Municipal Olympio Michael Gonzaga, em Paracatu. A autora nos brinda com um trabalho relevante e inovador, com destaque para suas fontes e para a retomada da bibliografia. Entretanto, uma questáo de fundo mereceria mais atenção: "A diferenciação dos papéis de classe no que se refere à mulher não parece ser táo forte quanto a de gênero, muito mais atuante no caso específico do qual estamos tratando" (p. 430). Mesmo considerando que mulheres de diferentes classes sociais vivenciam constrangimentos comuns por serem mulheres, não é possível 
afirmar que a classe social não seja um elemento fundamental para compreender as experiências dessas mulheres, diferenciadas por serem brancas ou negras, escravizadas ou livres. Uma análise intersecional daria conta dessa situação.

Com a mesma temática temos o trabalho "Casamento e 'descasamento': o vínculo matrimonial pode ser quebrado?”, de Dayse Lúcide Silva Santos, que enfoca a legislação brasileira sobre união e separação matrimonial, bem como apresenta e discute alguns estudos de caso, a partir de interessantíssima fonte documental, qual seja, os processos de nulidade de casamento e desquite ocorridos em Diamantina no século XX. Tendo em vista a "indissolubilidade matrimonial (...) pois somente a morte poderia quebrar o vínculo conjugal" (p. 449), a estratégia empregada era a tentativa de nulidade do casamento para serem autorizadas novas núpcias (o divórcio só foi aprovado no Brasil em 1977). Assim, a autora desvela os mecanismos de hierarquização de gênero. Se "O que Deus uniu o homem não separa”, era, e, em muita medida continua sendo, tarefa da mulher manter a família "estruturada”.

A maternidade é a temática dos dois próximos capítulos. Florisvaldo Paulo Ribeiro Júnior denuncia, a partir do estudo dos mundos do trabalho no início da república, como as novas representações sobre o papel da mulher busca fixá-la em um lugar tradicional. Trabalho coerente, que tem como fonte documental os jornais do início do século XX, no Triângulo Mineiro. Destaca-se a discussão sobre a perspectiva de laicização apontada pela República recém-instaurada e os debates em defesa do ensino religioso, como salvação da família. Qualquer semelhança com o contexto atual e as discussões sobre "ideologia de gênero" na educação, certamente, não será mera coincidência. Nesse ideário, a figura da mãe é idealizada e sacralizada. "Ou seja, se a natureza masculina se manifesta e os homens tornam-se viciosos, a culpa é das mulheres — mães, esposas e filhas - , que não souberam, ou não quiseram, cumprir sua missão..." (p. 491). Pois, afinal, "Um menino é o que d'elle faz sua mãe" (p. 488). Para o autor, a "atribuição de papéis, restrita ao lar, funcionou como prática que visou à interdição da palavra das mulheres no espaço público" e “o poder maternal foi mobilizado para esvaziar o conteúdo transformador de suas açóes" (p. 491-492), reorganizando o patriarcado. Valemo-nos de suas reflexóes para dialogar com o trabalho de Carla Denari Giuliani intitulado "A construção da maternidade e do casamento por mulheres adolescentes de Uberlândia (2000-2010)”. A autora busca recuperar a temática na história, mostrando que não é novidade a gravidez na adolescência mas que, em algum momento, foi transformado em problema social. A partir dos depoimentos de grávidas e mães jovens/adolescentes, Giuliani apresenta a maternidade precoce como resistência, poder feminino e enfrentamento à visão hegemônica sobre o assunto. Indagamos, como afirmou Ribeiro Jr., se esse "novo" poder (gravidez) provisório, que, em alguns casos traz uma condição de maior atenção/afeto às meninas/mulheres - inclusive com a ideia de que seria um caminho para "segurar" o companheiro - 
não acarreta, mais adiante, na fixação num lugar com menos poder para as mulheres. As adolescentes afirmam que a gravidez não é um problema, mas ponderamos como seria difícil dizer que ser mãe não é bom no contexto em que vivemos. Há, no trabalho de Giuliani, uma interessante retomada de como o feminismo interpretou a maternidade em diferentes momentos.

Com o capítulo "Escolas para mulheres: rainhas do lar e princesas. Minas Gerais, 1960-2012”, de Vera Lúcia Puga, chegamos ao final dessa bela obra, com um texto primoroso. Puga recupera as práticas educativas de Escolas Católicas, em Araguari (MG), mostrando que na rigorosa disciplina imposta por padres e freiras havia margem para as diferenciações e a inculcação das desigualdades de gêneros. Além dessas escolas religiosas, voltadas para filhos e filhas das elites, a autora analisa também a prática educativa de duas escolas voltadas para as classes populares, em que a formação sexista prevalece. Essa perspectiva formativa, com um currículo voltado à formaçáo para o "lar", dificultou o acesso de meninas, jovens e mulheres a outras escolas e profissóes mais valorizadas socialmente. Se essa era a realidade da educação escolar dos anos de 1960, a autora se surpreende - o que também pode ocorrer com o/a leitor/a — com a implantação, em pleno século XXI, da Escola de Princesas, na cidade de Uberlândia, com vistas à formação de meninas, crianças e adolescentes para: trabalhos domésticos, bom comportamento, cuidados pessoais. Assim, Puga alerta: "Os retornos ao que existiu, à dependência e submissão feminina ao masculino, à volta da mulher ao lar, para a educação dos filhos e cuidados da casa e marido ou companheiro estáo presentes no cotidiano deste século XXI" (p. 540). Desnaturalizar e desconstruir esse lugar da mulher é a tarefa do feminismo, que o livro ajuda a cumprir.

Sem dúvida História das mulheres e do gênero em Minas Gerais é leitura obrigatória para estudiosas/os que querem compreender melhor como as mulheres (sobre)viveram em Minas Gerais aos ditames de uma sociedade patriarcal, autoritária e misógina. E pode ser boa companhia para quem quiser saber um pouco mais sobre gente, porque falar de gênero é falar das relaçôes que construímos entre nós, seres humanos. 